\title{
Loneliness, loss, and social support among cognitively intact older people with cancer, living in nursing homes - a mixed-methods study
}

\author{
Jorunn Drageset ${ }^{1,2}$ \\ Geir Egil Eide ${ }^{2,3}$ \\ Elin Dysvik ${ }^{4}$ \\ Bodil Furnes ${ }^{4}$ \\ Solveig Hauge ${ }^{5}$
}

'Faculty of Health and Social Sciences, Bergen University College, Bergen, Norway; ${ }^{2}$ Department of Global Public Health and Primary Care, University of Bergen, Bergen, Norway; ${ }^{3}$ Centre for Clinical Research, Haukeland University Hospital, Bergen, Norway; ${ }^{4}$ Department of Health Studies, Faculty of Social Sciences, University of Stavanger, Stavanger, Norway; ${ }^{5}$ Faculty of Health and Social Studies and Centre for Caring Research Southern Norway, Telemark University College, Porsgrunn, Norway
Correspondence: Jorunn Drageset Faculty of Health and Social Sciences, Bergen University College, Inndalsveien 28, N-5063 Bergen, Norway Email jorunn.drageset@hib.no
This article was published in the following Dove Press journal:

Clinical Interventions in Aging

25 September 2015

Number of times this article has been viewed

Background: Loneliness is a significant psychosocial effect following a cancer diagnosis and may prevent people from engaging in social activities, thus creating difficulties in interpersonal relationships. This study investigated loneliness and social support among cognitively intact nursing home residents with cancer by using a quantitatively driven mixed-methods design with sequential supplementary qualitative components.

Methods: The quantitative component consisted of face-to-face interviews of 60 nursing home residents ( $\geq 65$ years) using the one-item Loneliness Scale and the Social Provisions Scale. The supplementary psychosocial component consisted of qualitative research interviews about experiences related to loneliness with nine respondents.

Results: The quantitative results indicated that reassurance of worth was associated with loneliness. The experience of loneliness was identified by the following: loneliness that was dominated by a feeling of inner pain, feeling of loss, and feeling small. Loneliness was alleviated by the following: being engaged in activities, being in contact with other people, and occupying oneself.

Conclusion: Enhancing the lives of nursing home residents with cancer requires attending to the residents' experience of loneliness and social relationships in a targeted and individualized manner. This might require screening all nursing home residents for early detection of loneliness. Revealing factors that may contribute to or reduce loneliness improves the ability to enhance people's lives.

Keywords: loneliness, social support, nursing homes, older adults, mixed-methods

\section{Introduction}

Loneliness is a subjective and painful feeling ${ }^{1}$ common among older people, ${ }^{2-6}$ with a reported prevalence of $40 \%$ in the community ${ }^{6}$ and $56 \%$ in nursing homes, ${ }^{2}$ and often reported among older people with cancer. ${ }^{7-9}$ It has also been shown to be a significant psychosocial consequence following a cancer diagnosis., ${ }^{7,8,10,11}$ Adverse effects of cancer may prevent people from engaging in social activities, thus creating difficulties in interpersonal relationships, ${ }^{12-14}$ which ultimately may contribute to loneliness. ${ }^{6,15}$

Loneliness may result from a lack of satisfying human relationships ${ }^{16}$ or from lack of belongingness. ${ }^{17}$ Weiss ${ }^{18}$ conceptualized loneliness into two categories: emotional and social, which can coexist or occur independently. Emotional isolation can result from the absence of a close person such as a partner or friend. Lack of social integration, such as not interacting with others or isolating oneself from former friends, can cause social loneliness. Weiss' ${ }^{18}$ theory of social provision is based on the assumption that individuals seek specific social provision to avoid emotional and social loneliness. 
Weiss ${ }^{18}$ proposed six basic provisions: attachment, social integration, opportunities for nurturance, reassurance of worth, a sense of reliable alliance, and obtaining guidance. These provisions are obtained in different relationships, and the need for specific relational provisions may differ by age, stage of life, and change in specific environmental conditions. When admitted to a nursing home, $10 \%-26 \%$ of the residents have cancer. ${ }^{19,20}$ Common symptoms include anorexia, fatigue, nausea, vomiting, and pain; $;^{14,21,22}$ pain is often untreated..$^{23,24}$ The residents with cancer are frail and often dependent in activities of daily living ${ }^{25,26}$ and report more symptoms of anxiety and depression than other residents. ${ }^{26}$ Compared with residents without cancer, residents with cancer reported lower health-related quality of life (HRQOL) $)^{19}$ and lower HRQOL than older people with cancer who are at the end of life in hospitals or at home. ${ }^{14}$

Similar to other nursing home residents, those with cancer may also have experienced many losses, including moving from their home, the death of a spouse, social changes in relatives and friends, and/or declining health. Such conditions may deeply affect residents' lives and contribute to the experience of loss and, in turn, loneliness. Loss follows an event that is perceived to be negative by the individuals involved and results in long-term changes to their social situations, relationships, or cognition. ${ }^{27}$ Social relationships and social support are essential for coping with loss, ${ }^{27}$ reducing loneliness among nursing home residents, ${ }^{2}$ and contributing positively to people with cancer. ${ }^{7,15}$

Our literature review indicates that loneliness is a significant psychosocial effect following a cancer diagnosis ${ }^{7,8,10,11}$ and that adverse effects of cancer may prevent people from engaging in social activities, thus creating difficulties in interpersonal relationships. ${ }^{12-14}$ We therefore hypothesized that nursing home residents with cancer may be lonely and that social support is essential to reduce loneliness. However, to our knowledge, few studies have investigated this association and simultaneously explored the residents' own experience in a mixed-methods perspective. We therefore investigated how nursing home residents with cancer define, perceive, and cope with the experience of loneliness and social isolation. This knowledge may improve the care of nursing home residents with cancer.

\section{Aim of the study}

This study investigated loneliness and social support among cognitively intact nursing home residents with cancer and their experience with loneliness, social support, and loss. The specific research questions were as follows: how are sociodemographic and illness variables, social support, and loneliness associated? How do nursing home residents with cancer describe experiences of loneliness and loss? Can findings from the qualitative analysis enhance the quantitative results?

\section{Methods \\ Design and population}

This study used a quantitatively driven mixed-methods design with qualitative sequential components, quantitative and qualitative. ${ }^{28}$ The theoretical drive, or the deductive direction of a research project, guides the quantitative methodological core. ${ }^{29}$ This in turn enables investigation of quantitative measures of loneliness as well as social support subdimensions for testing and refuting already developed concepts.

The quantitative core component consisted initially of 60 respondents interviewed face-to-face, with the one-item Loneliness Scale and the Social Provisions Scale (SPS). ${ }^{30,31}$ The supplementary component consisted of nine qualitative research interviews about life experiences related to loneliness and psychosocial topics from the same respondents. This qualitative component enabled deeper exploration of the loneliness phenomenon for significant relationships and may enhance the quantitative results.

Once the quantitative core components as well as the supplementary qualitative components were analyzed, the findings on the core component were described. The final descriptions from quantitative and qualitative components were then integrated, and these constituted the results on which the discussion is based (Figure 1).

This research is part of a larger study ( $\mathrm{n}=227$ patients, 167 without cancer and 60 with cancer) conducted in 2004-2005,, 2 with follow-up until 2011. At the end of follow-up, 19 of the 227 nursing home residents were still alive, and of these, nine residents with cancer were included in the qualitative part of the study. This study used quantitative data from 60 respondents with a cancer diagnosis from the first inclusion in 2004-2005 and qualitative data from nine respondents with a cancer diagnosis from follow-up in 2011. The inclusion criteria in both cases were: a diagnosis of cancer at inclusion, 65 years and older, cognitively intact, capable of conversing and residing in the nursing home for at least 6 months. Cognitively intact was defined as having a Clinical Dementia Rating (CDR) score $\leq 0.5 .{ }^{33}$ The CDR was developed as a staging instrument for dementia and is scored as no $(0)$, questionable (0.5), mild (1), moderate (2), and severe (3) dementia, and the overall level of dementia is derived by using a standard algorithm. ${ }^{34}$ Trained nurses who had observed the residents for at least 4 weeks assessed CDR and were instructed to base 


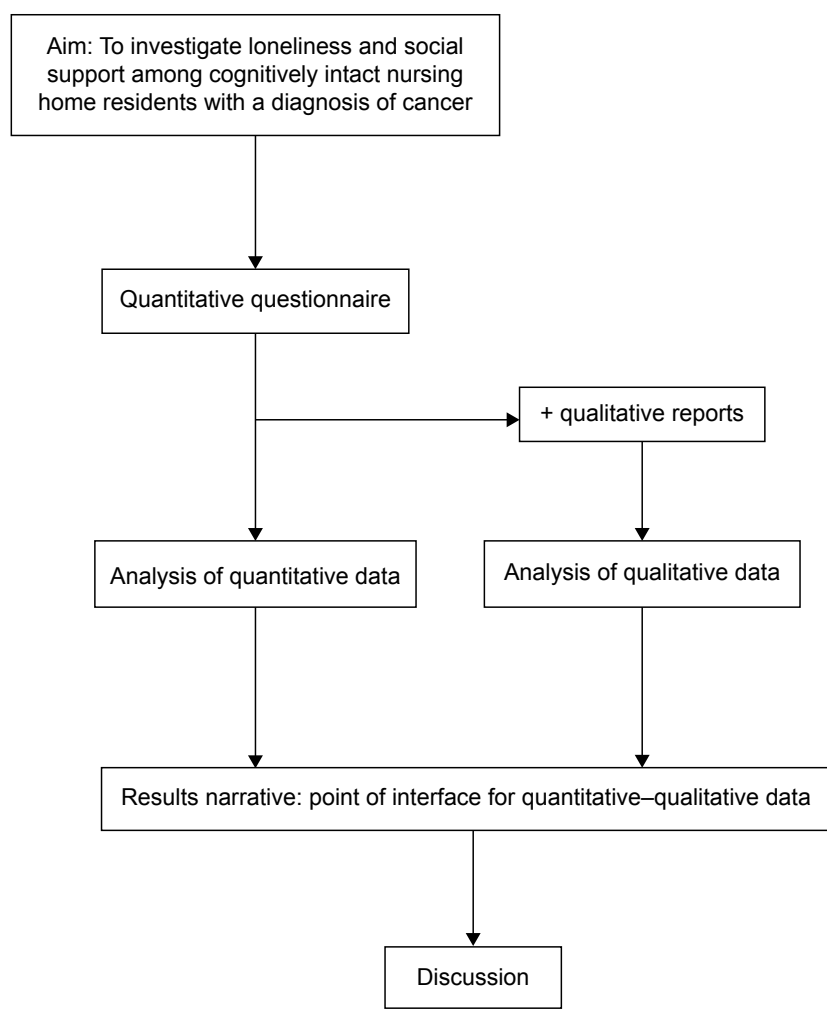

Figure I Schematic overview of quantitative-qualitative mixed-methods design for testing and refuting already developed concepts.

Notes: The left pathway illustrates the core component of the project (quantitative deductive drive). The right pathway illustrates the supplemental components of the project (qualitative inductive drive). The point of interface is the position at which the core and the supplemental components meet. The "results" refers to write-up of the core component findings with the addition of results of the supplemental components.

their CDR scoring on mental functioning and not to include physical frailty. The CDR has shown high interrater reliability for physicians and other health professionals. ${ }^{35}$ Exclusion criteria were as follows: lived less than 6 months in a nursing home, CDR score $>0.5$, and residents for whom a doctor or nurse had indicated that the resident could not converse with the researcher based on assessing their general health status. A primary care nurse invited the residents to participate.

\section{Ethical approval}

The sample was collected during 2009-2010. Informed consent was obtained. The Western Norway Regional Committee for Medical and Health Research Ethics and the Norwegian Social Science Data Services approved the study (REK Vest number 62.03/2009/1550).

\section{Data collection Quantitative data}

Face-to-face interviews were conducted in the respondent's room or at another appropriate location in the nursing home. The principal investigator (JD) collected the data, which included reading the questions to the participants, circling the indicated answer, and recording the demographic information. This was necessary since many residents had problems holding a pen and/or had impaired vision. Each participant was given a large-type version of the questionnaire to improve its readability. The interviewer made sure that the respondents understood all the questions.

\section{Assessment instruments Illnesses}

Groll's index (Functional Comorbidity Index, FCI) was used to classify the diagnoses. $\mathrm{FCI}$ is a clinically based measure developed by Groll et al. ${ }^{36}$ The FCI includes 18 diagnoses scored present $(=1)$ and not present $(=0)$ and has a maximum score of 18 .

\section{Loneliness}

Loneliness was assessed by the global question: "Do you feel lonely?". This question has been used in studies among older people in nursing homes ${ }^{2,37}$ and people living at home. ${ }^{37,38}$ Responses were scored using the following categories: $1=$ often, $2=$ sometimes, $3=$ rarely, and $4=$ never. The higher the participant scored, the lower the level of loneliness. For the statistical analysis, variables were dichotomized, with response categories 1 and 2 combined to denote the score of $0=$ lonely, and 3 and 4 combined to denote the score of $1=$ not lonely.

\section{Social support}

We assessed social support using the revised SPS. ${ }^{31}$ The SPS contains 24 items, four for each of the six social provisions described by Weiss. ${ }^{39}$ The response format has a four-point rating scale: "strongly disagree", "disagree", "agree", and "strongly agree". According to Cutrona and Russell, ${ }^{31}$ Andersson and Stevens, ${ }^{40}$ and Mancini and Blieszner, ${ }^{41}$ four of the original six subscales were selected: "attachment" (emotional closeness from which one drives a sense of security), "social integration" (relationships in which the person shares concerns and common interests), "opportunities for nurturance" (being responsible for the care of others), and "reassurance of worth" (a sense of competence and esteem). High scores indicate high social provision. The SPS, with four subdimensions "attachment", "social integration", "nurturance", and "reassurance of worth" has been used in studies of older people living in the community ${ }^{35,42,43}$ and nursing home residents. ${ }^{2,36}$ 


\section{Qualitative data}

Qualitative data were collected through individual interviews. A semistructured interview guide, based on one of the authors' previous research findings, was developed. ${ }^{1}$ Informants were asked about what they consider loneliness to be, what factors they thought contributed to loneliness, how they thought it was possible to manage loneliness, and what they thought may help to manage loneliness. Each resident was interviewed in their room for 45-90 minutes. The interviewer (the first author) conducted the interviews as conversations, prompting the participants to describe their experience. The interviewer asked spontaneous follow-up questions based on the respondents' answers to the questions. Interviews were recorded and transcribed verbatim. This resulted in a data set of 50 pages of text.

\section{Statistical analysis}

Descriptive statistics were calculated for the demographic variables, comorbidity, loneliness, and social support subdimensions and reported means, standard deviations (SDs) and proportions. Reliability of each social support dimension was calculated using Cronbach's alpha. Logistic regression was used to study the association between the social support subdimensions and loneliness.

Social support and comorbidity were included in the model as continuous covariates; the remainder of the variables (sex, age, marital status, education, and Groll's index $)^{36}$ were coded as categorical. The results are presented as odds ratios and $95 \%$ confidence intervals. Unadjusted and fully adjusted estimates are given to study the potential confounding of effects. Further, a final, simpler model was identified by backward stepwise selection of variables significant at the 0.05 level.

IBM SPSS Statistics (Version 21.0) (IBM Corporation, Armonk, NY, USA) was used for all statistical analysis, with $P<0.05$ to determine statistical significance.

\section{Qualitative data analysis}

Data from the interviews were analyzed by using elements of qualitative content analysis. ${ }^{44}$ The analytical process occurred in six stages: 1) transcription of the interview, 2) open independent reading of all materials to gain an overall impression of the text, 3) identification of meaning units, 4) categorization, 5) abstracting two subthemes and theme, and 6) reflection and discussion. Seventeen categories were identified. The categories were further abstracted to six subthemes and two themes. An example of the analytical process is that the quote from one interview "When I'm lonely, I go to my room and sit down and cry. Yes, I do that
Table I Overview of categories, subthemes, and themes in qualitative analyses

\begin{tabular}{lll}
\hline Categories & Subthemes & Themes \\
\hline $\begin{array}{l}\text { Meaningless life } \\
\text { Not thriving }\end{array}$ & Feelings of inner pain & $\begin{array}{c}\text { Experiencing } \\
\text { loneliness }\end{array}$ \\
$\begin{array}{l}\text { Loss of important others } \\
\text { Loss of health } \\
\text { Loss of home } \\
\text { Overlooked }\end{array}$ & Feelings of loss & \\
$\begin{array}{l}\text { Marginalized } \\
\text { No one cares }\end{array}$ & Feeling small & \\
$\begin{array}{l}\text { Someone to care about } \\
\text { The outside world }\end{array}$ & The importance of & Decreasing \\
Something to do & being engaged & loneliness \\
Family & The significance of & \\
The nurses and care workers & contact with other & \\
Use telephone & people & \\
Radio and television & The importance of & \\
Read newspaper and books & occupying oneself & \\
\hline
\end{tabular}

often". was categorized as feeling sad and abstracted to the subtheme feeling of inner pain.

Table 1 shows an overview of categories, subthemes, and themes in qualitative analysis.

\section{Results}

\section{Respondents' characteristics}

Of the 60 respondents, 39 (65\%) were women. The mean age was 85.3 years (SD: 6.7). The mean number of comorbid illnesses was 2.2 (median: 2.0, SD: 1.3, range: 0-6) (Table 2). The most common diagnoses were musculoskeletal (60\%), congestive heart failure or other heart diseases (53\%), and cerebrovascular disease (34\%).

Loneliness was reported by $57 \%$ of the residents, $60 \%$ among widows and widowers (data not shown).

\section{Quantitative findings}

In unadjusted analysis, marital status was associated with loneliness $(P=0.04)$. In fully adjusted multiple regression analysis of the sociodemographic variables, Groll's index $(P=0.02)$, marital status $(P=0.05)$ and the social support subdimension reassurance of worth $(P=0.004)$ were significantly correlated with loneliness.

In the final model, based on the background selection procedure, marital status ( $P=0.02)$, Groll's index $(P=0.02)$, and the subdimension reassurance of worth $(P<0.001)$ were significantly associated with loneliness (Table 3 ).

Cronbach's alpha for the social support subdimensions ranged from 0.76 to 0.88 , with reassurance of worth the highest and attachment the lowest. 
Table 2 Personal characteristics of the 60 respondents in the Bergen Nursing Home Study 2004-2005

\begin{tabular}{ll}
\hline Characteristic & $\begin{array}{l}\text { With cancer }(\mathbf{n}=\mathbf{6 0}) \\
\text { Number }(\%)\end{array}$ \\
\hline Sex $^{\mathrm{a}}$ & \\
Men & $21(35.0)$ \\
Women & $39(65.0)$ \\
Age (years) & \\
$65-74$ & $3(5.0)$ \\
$75-84$ & $24(40.0)$ \\
$85-94$ & $28(46.7)$ \\
$\geq 95$ & $5(8.3)$ \\
Marital status & \\
Married or cohabiting & $18(30.0)$ \\
Unmarried & $8(13.3)$ \\
Divorced & $4(6.7)$ \\
Widowed & $30(60.1)$ \\
Education & \\
Primary school & $22(36.7)$ \\
$<3$ years after primary school & $31(51.7)$ \\
$\geq 3$ years after primary school & $7(11.7)$ \\
Groll's index (FCl') & \\
FCl $\geq I$ & $53(88.3)$ \\
FCl $=0$ & $7(11.7)$ \\
Cancer & \\
Breast & $12(20.0)$ \\
Colorectal & $12(20.0)$ \\
Prostate & $7(11.7)$ \\
Other & $34(56.7)$ \\
\hline Notes Studen'stterst &
\end{tabular}

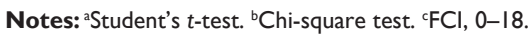

Abbreviation: $\mathrm{FCl}$, Functional Comorbidity Index.

\section{Qualitative findings}

\section{Experiencing loneliness}

Some of the participants described loneliness as painful, almost like something they try to keep to themselves. The most typical example from each category is presented in the following:

When I'm lonely, I go to my room and sit down and cry. Yes, I do that often.

Some residents described loneliness as loss of health, home, or important people.

My health is poor; I cannot walk. My health is failing; it is no fun.

Yes, one part of it is that you lose your environment [by moving to a nursing home]. I lost my spouse; others lose other things like work or something. So you lose all the time.

Furthermore, the way they described loneliness may indicate that loneliness affected their self-image and selfesteem.

When you are lonely, you feel very small, terribly small. You are so small that almost nothing is left of you.

You sit alone in your room, and you have no one to talk to, you have only yourself. When you feel very small, horribly small.

Table 3 Logistic regression models for loneliness and for the SPS for nursing home residents

\begin{tabular}{|c|c|c|c|c|c|c|c|c|c|}
\hline & \multicolumn{3}{|c|}{ Unadjusted $^{\mathrm{a}}$} & \multicolumn{3}{|c|}{ Fully adjusted $^{\mathrm{b}}$} & \multicolumn{3}{|c|}{ Final model ${ }^{c}$} \\
\hline & \multicolumn{3}{|l|}{ ratio $^{a}$} & \multicolumn{3}{|l|}{ ratio $^{a}$} & \multicolumn{3}{|l|}{ ratio $^{a}$} \\
\hline Sex & & & 0.956 & & & & & & \\
\hline Women & I & Reference & & 1 & Reference & 0.669 & & & \\
\hline Men & 0.97 & $(0.33,2.8)$ & & 0.87 & $(0.11,31.55)$ & & & & \\
\hline Age (years) & & & 0.829 & & & 0.407 & & & \\
\hline $65-74$ & 1 & Reference & & 1 & Reference & & & & \\
\hline $75-84$ & 3.0 & $(0.15,59.80)$ & & 0.01 & $(0.00,2.55)$ & & & & \\
\hline $85-94$ & 1.27 & $(0.18,9.02)$ & & 0.01 & $(0.00,2.27)$ & & & & \\
\hline$\geq 95$ & 0.9 & $(0.14,6.78)$ & & 0.01 & $(0.00,5.01)$ & & & & \\
\hline Education & & & 0.711 & & & 0.200 & & & \\
\hline Primary school & 1 & Reference & & I & Reference & & & & \\
\hline$<3$ years after primary school & 2.03 & $(0.33,13.15)$ & & 0.22 & $(0.33,1.52)$ & & & & \\
\hline$\geq 3$ years after primary school & 2.06 & $(0.35,12.28)$ & & 0.07 & $(0.00,1.64)$ & & & & \\
\hline Marital status & & & 0.043 & & & 0.048 & & & 0.022 \\
\hline Married or cohabiting & I & Reference & & 1 & Reference & & 1 & & \\
\hline Unmarried & 6.07 & $(1.67,22.12)$ & & 0.05 & $(0.00,1.99)$ & & 0.16 & $(0.02,1.22)$ & \\
\hline Divorced & 1.40 & $(0.27,7.15)$ & & 0.55 & $(0.1,25.99)$ & & 0.18 & $(0.01,4.06)$ & \\
\hline Widowed & 0.78 & $(0.7 I, 8.52)$ & & 0.01 & $(0.00,0.25)$ & & 0.11 & $(0.02,0.53)$ & \\
\hline Groll's index & 1.19 & $(0.80,1.79)$ & 0.394 & 2.84 & $(1.19,6.76)$ & 0.019 & & & \\
\hline \multicolumn{10}{|l|}{ Social provision scale ${ }^{d}$} \\
\hline Attachment & 0.97 & $(0.92,1.31)$ & 0.284 & 1.05 & $(0.70,1.59)$ & 0.830 & & & \\
\hline Social integration & 0.97 & $(0.95,1.30)$ & 0.196 & 0.87 & $(0.96,1.08)$ & 0.403 & & & \\
\hline Reassurance of worth & 1.55 & $(1.10,2.14)$ & 0.008 & 2.26 & $(1.30,3.91)$ & 0.004 & 1.64 & $(1.16,2.35)$ & $<0.001$ \\
\hline Nurturance & 1.12 & $(0.93,1.32)$ & 0.246 & 0.83 & $(0.55,1.25)$ & 0.371 & & & \\
\hline
\end{tabular}

Notes: aUnadjusted for sex, age group, educational level, marital status, comorbidity; bfully adjusted for sex, age group, educational level, marital status, comorbidity; 'final model adjusted for sex, age group, educational level, marital status, comorbidity; 'SPS 4-I6, higher score better score. P-value is derived from likelihood ratio test. The bold values are the significant outcomes.

Abbreviations: $\mathrm{Cl}$, confidence interval; SPS, Social Provisions Scale. 


\section{Decreasing loneliness}

The residents described good advice to counteract loneliness, such as remaining engaged.

I'm not lonely because I am engaged in what is said and done around me. A lonely person can read a newspaper, read a book and listen to radio and television. It is possible to do something.

Interest from other people was of great importance, and major activities were not necessarily needed.

Lonely I am. The entire day is lonely. Except now, something like this, you come in and interview. It's a bright spot. You get the opportunity to tell your experience.

Having contact with staff and with family was important to reduce loneliness.

The nurses and care workers, they are the most important, but they do not have time to stop and talk.

Many residents emphasized the importance of visits from children and grandchildren. Nevertheless, they recognized that their family could not come every day. In such situations, the phone was a lifeline.

However, although they appreciated contact with the family, they also were afraid of being too intrusive.

I have family I can call. However, I cannot call all the time.

Some of the participants described that they considered it important to occupy themselves in order to ease the loneliness feeling.

I have my TV and my radio. That has helped me a lot.

\section{Discussion}

The findings of the quantitative and the qualitative data analysis were combined to produce a deeper understanding of the residents' experiences. Both data sets showed that loneliness is prominent and that social relationships are important for participants in coping with loneliness. The findings from both the quantitative data and the qualitative data highlight that the sense of competence and self-esteem are important for loneliness. The quantitative data showed that the social support dimension, reassurance of worth, including the sense of competence and self-esteem, is important for reducing loneliness. The qualitative data provided descriptions of the loneliness experience and participants' coping strategies.

This study showed that $57 \%$ of cognitively intact nursing home residents with cancer reported loneliness. In addition, the supplementary components indicate that the experience of loneliness of residents with cancer could be seen as a part of feeling small, feeling of loss, and inner pain. Further, marital status and the social support subdimension, reassurance of worth, were positively correlated with loneliness (Table 3).
Several studies have reported loneliness among nursing home residents with cancer, ${ }^{7-9}$ especially among those with increasing time since diagnosis ${ }^{7}$ and the period after the initial treatment. ${ }^{10}$ Studies have also reported that loneliness is not attributed to cancer-related factors such as cancer site, type of treatment, and stage of diagnosis. ${ }^{7,10}$ However, this study did not investigate cancer-related factors and time since diagnosis and, therefore, cannot draw any conclusions about these associations.

Qualitative data supported the feeling of loneliness obtained from the quantitative data, and such feelings were described as "painful". The residents' experiences are in accordance with Hauge and Kirkevold's ${ }^{1}$ description of loneliness as "an unpleasant feeling". In addition, the participants appeared to try to hide their pain by withdrawing to their rooms when they felt lonely. This is similar to the findings presented in other studies, such as feeling embarrassed ${ }^{45}$ or shameful ${ }^{46}$ or withdrawal when feeling lonely. ${ }^{47}$

The experience of loneliness is reported among older people with cancer, and important noncancer-related determinants include marital status, functional limitation, and chronic disease. ${ }^{7}$ In our study, marital status was significantly associated with loneliness, and $60 \%$ of our sample were widows or widowers. The death of a spouse, social changes, and failing health may give feelings of loss, ${ }^{27}$ and loss caused by the death of a loved one is connected to loneliness. ${ }^{7}$ Our results show a significant association between loneliness and diseases in the adjusted model (Table 2). The residents described this experience as "My health is poor; I cannot walk" and "My health is failing; this is no fun". Although failing health and functional impairment are important determinants of the feeling of loneliness not directly related to cancer, ${ }^{7}$ they could also be indirectly related to cancer because cancer causes fatigue, weight loss, and worse general health. ${ }^{19,25,26}$ In addition, having a cancer diagnosis may represent an additional burden that may limit functioning beyond normal aging processes. ${ }^{25}$

The social support subdimension, reassurance of worth, was significantly associated with loneliness. Both individualized support and social group support are important for reducing loneliness among older people. ${ }^{48}$ Our findings suggest that a sense of competence and self-esteem influences loneliness. This was particularly visible in the statement by a resident expressing loneliness as a feeling of being "[...] so small that almost nothing is left of you". Such descriptions indicate that loneliness can affect a person's self-esteem, as also outlined in Weiss ${ }^{18}$ theory; he emphasized that the feeling of being needed and valued is essential to strengthening self-esteem. ${ }^{39}$ In our study, the nursing home residents said that contact with nurses and care workers and visits from 
family members were most important in revealing the loneliness experience and thereby also strengthen self-esteem. Most residents depended on help from nursing personnel, and thus were in daily contact with caregivers. The question is whether the nursing care personnel help and support the residents' self-esteem in their daily contact.

In addition, the residents said that such activities as reading, telephone calls, or listening to radio or television could ease their state. This is in accordance with Pettigrew and Roberts ${ }^{49}$ and Kirkevold et al' $\mathrm{s}^{50}$ findings that the main coping strategies among lonely people were 1) social interaction and 2) social activities. Person-centered care that respects each resident's values and attitudes is needed, including supporting the residents in maintaining their close relationships and helping to realize their activities.

\section{Methodological considerations}

The mixed-methods design enabled us to clarify more broadly the various aspects of the phenomena of loneliness. ${ }^{28}$ Using both quantitative and qualitative methods provided more comprehensive answers to our research questions. The supplementary component (the qualitative data analysis) informed and supported the core component (the quantitative data). In this way, the mixed-methods design validated and extended our findings, in accordance with the rules inherent in each paradigm, as described by Morse et al. ${ }^{29}$

To enhance credibility, experienced qualitative researchers transformed the written reports from meaning units into themes and discussed the interpretation of their textual meaning. However, this study included only residents with cancer, so the data do not offer insight into whether the answers regarding loneliness resulted from cancer, nursing home residence, or old age in general. We measured loneliness by using one question. The benefits of such a self-report measure include being easy to use in clinical settings, easy to understand, and asking directly about feeling lonely. However, this question presumes that respondents understand the concept of loneliness, even though the nature and meaning of the concept probably vary between groups of people and over time. Further, using one item does not differentiate between emotional and social loneliness.

The strengths of this study are that all the participants were interviewed face-to-face, thus preventing possible misunderstandings of meaning, which adds to the study's validity. The interviewees reported their narratives about loneliness themselves, which probably strengthens the validity of the meanings in the text. Further, this study followed a cohort $(n=60)$ of frail, but cognitively intact nursing home residents from 2004 to 2011, and nine nursing home residents with cancer were still alive at the end of follow-up. Based on this, we found meaningful qualitative findings that extended and supported the quantitative results.

\section{Conclusion and implications}

More than half the nursing home residents with cancer reported loneliness, and the social support subdimension, reassurance of worth, was associated with reduced loneliness. A mixed-methods design contributed to nuanced and detailed information about the meaning of loneliness, and the supplementary component informs and supports the core component. The combined findings call for several improvements in care among nursing home residents with cancer, which more appropriately reflects their concerns aimed at alleviating loneliness and loss.

To improve the situation of nursing home residents with cancer diagnosis, more attention should be paid to the residents' experience of loneliness and their social relationships. To do this, we suggest screening all nursing home residents for early detection of loneliness and social relationships. Then, one challenge for health professionals is to help the residents to reduce loneliness. The care should be based on the people's needs and not on what care personnel believe they need, because residents' autonomy and integrity should be respected. In addition, the health professionals need to be aware of the extra burden of having cancer.

\section{Acknowledgment}

Jorunn Drageset received a postdoctoral fellowship from the Norwegian Cancer Society.

\section{Disclosure}

The authors report no conflicts of interest in this work.

\section{References}

1. Hauge S, Kirkevold M. Older Norwegians' understanding of loneliness. Int J Qual Stud Health Well-being. 2010;5. doi:10.3402/qhw. v5i1.4654.

2. Drageset J, Kirkevold M, Espehaug B. Loneliness and social support among nursing home residents without cognitive impairment: a questionnaire survey. Int J Nurs Stud. 2011;48(5):611-619.

3. Iecovich E, Jacobs JM, Stessman J. Loneliness, social networks, and mortality: 18 years of follow-up. Int J Aging Hum Dev. 2011;72(3): 243-263.

4. Kvaal K, Halding AG, Kvigne K. Social provision and loneliness among older people suffering from chronic physical illness. A mixed-methods approach. Scand J Caring Sci. 2014;28(1):104-111.

5. Luanaigh CO, Lawlor BA. Loneliness and the health of older people. Int J Geriatr Psychiatr. 2008;23(12):1213-1221.

6. Routasalo PE, Savikko N, Tilvis RS, Strandberg TE, Pitkala KH. Social contacts and their relationship to loneliness among aged people - a population-based study. Gerontology. 2006;52(3):181-187.

7. Deckx L, van den Akker M, Buntinx F. Risk factors for loneliness in patients with cancer: a systematic literature review and meta-analysis. Eur J Oncol Nurs. 2014;18(5):466-477. 
8. Fox CM, Harper AP, Hyner GC, Lyle RM. Loneliness, emotional repression, marital quality, and major life events in women who develop breast cancer. J Community Health. 1994;19(6):467-482.

9. Rokach A. Loneliness in cancer and multiple sclerosis patients. Psychol Rep. 2004;94(2):637-648.

10. Rosedale M. Survivor loneliness of women following breast cancer. Oncol Nurs Forum. 2009;36(2):175-183.

11. Wyatt G, Friedman LL. Long-term female cancer survivors: quality of life issues and clinical implications. Cancer Nurs. 1996;19(1):1-7.

12. Duncan JG, Forbes-Thompson S, Bott MJ. Unmet symptom management needs of nursing home residents with cancer. Cancer Nurs. 2008; 31(4):265-273.

13. Foster C, Wright D, Hill H, Hopkinson J, Roffe L. Psychosocial implications of living 5 years or more following a cancer diagnosis: a systematic review of the research evidence. Eur J Cancer Care (Engl). 2009;18(3): 223-247.

14. Jordhoy MS, Saltvedt I, Fayers P, Loge JH, Ahlner-Elmqvist M, Kaasa S. Which cancer patients die in nursing homes? Quality of life, medical and sociodemographic characteristics. Palliat Med. 2003;17(5):433-444.

15. Yildirim Y, Kocabiyik S. The relationship between social support and loneliness in Turkish patients with cancer. J Clin Nurs. 2010;19(5-6): 832-839.

16. Andersson L. Loneliness research and interventions: a review of the literature. Aging Ment Health. 1998;2(4):264-274.

17. Nicholson NR Jr. Social isolation in older adults: an evolutionary concept analysis. $J$ Adv Nurs. 2009;65(6):1342-1352.

18. Weiss RS. Loneliness. The Experience of Emotional and Social Isolation. Cambridge, MA: Massachusetts Institute of Technology; 1973.

19. Drageset J, Eide GE, Ranhoff AH. Cancer in nursing homes: characteristics and health-related quality of life among cognitively intact residents with and without cancer. Cancer Nurs. 2012;35(4):295-301.

20. Rodin MB. Cancer patients admitted to nursing homes: what do we know? J Am Med Direct Assoc. 2008;9(3):149-156.

21. Brandt HE, Deliens L, Ooms ME, van der Steen JT, van der Wal G, Ribbe MW. Symptoms, signs, problems, and diseases of terminally ill nursing home patients: a nationwide observational study in the Netherlands. Arch Intern Med. 1995;165(3):314-320.

22. Duncan JG, Bott MJ, Thompson SA, Gajewski BJ. Symptom occurrence and associated clinical factors in nursing home residents with cancer. Res Nurs Health. 2009;32(4):453-464.

23. Bernabei R, Gambassi G, Lapane K, et al. Management of pain in elderly patients with cancer. SAGE Study Group. Systematic Assessment of Geriatric Drug Use via Epidemiology. JAMA. 1998;279(23): $1877-1882$.

24. Deandrea S, Montanari M, Moja L, Apolone G. Prevalence of undertreatment in cancer pain. A review of published literature. Ann Oncol. 2008;19(12):1985-1991.

25. Bourbonniere M, Van Cleave JH. Cancer care in nursing homes. Semin Oncol Nurs. 2006;22(1):51-57.

26. Buchanan RJ, Barkley J, Wang S, Kim M. Analyses of nursing home residents with cancer at admission. Cancer Nurs. 2005;28(5):406-414.

27. Harvey J. Perspectives on Loss. London, UK: Taylor \& Francis; 1998.

28. Morse JM, Niehaus L. Mixed Method Design: Principles and Procedures. Walnut Creek, CA: Left Coast Press; 2009.

29. Morse JM, Niehaus L, Wolfe RR, Wilkins S. The role of the theoretical drive in maintaining validity in mixed-method research. Qual Res Psychol. 2006;3(4):279-291.

\section{Clinical Interventions in Aging}

\section{Publish your work in this journal}

Clinical Interventions in Aging is an international, peer-reviewed journal focusing on evidence-based reports on the value or lack thereof of treatments intended to prevent or delay the onset of maladaptive correlates of aging in human beings. This journal is indexed on PubMed Central, MedLine,
30. Andersson L. Intervention against loneliness in a group of elderly women: a process evaluation. Hum Relations. 1984;37(4):295-310.

31. Cutrona CE, Russell DW. The provisions of social relationships and adaptation to stress. In: Jones WH, Perlman D, editors. Advances in Personal Relationships. A Research Annual I. Greenwich, CT: Jai Press; 1987:37-67.

32. Drageset J, Natvig GK, Eide GE, Bondevik M, Nortvedt MW, Nygaard HA. Health-related quality of life among old residents of nursing homes in Norway. Int J Nurs Pract. 2009;15(5):455-466.

33. Hughes CP, Berg L, Danziger WL, Coben LA, Martin RL. A new clinical scale for the staging of dementia. Br J Psychiatr. 1982;140(6): 566-572.

34. Morris JC. The Clinical Dementia Rating (CDR): current version and scoring rules. Neurology. 1993;43(11):2412-2414.

35. McCulla MM, Coats M, Van Fleet N, Duchek J, Grant E, Morris JC. Reliability of clinical nurse specialists in the staging of dementia. Arch Neurol. 1989;46(11):1210-1211.

36. Groll DL, To T, Bombardier C, Wright JG. The development of a comorbidity index with physical function as the outcome. J Clin Epidemiol. 2005;58(6):595-602.

37. Bondevik M, Skogstad A. The oldest old, ADL, social network, and loneliness. West J Nurs Res. 1998;20(3):325-343.

38. Holmen K, Ericsson K, Andersson L, Winblad B. Loneliness among elderly people living in Stockholm: a population study. J Adv Nurs. 1992; 17(1):43-51.

39. Weiss RS. The provisions of social relationships. In: Rubin Z, editor. Doing Unto Others. Englewood Cliffs, NJ: Prentice-Hall; 1974: $17-26$.

40. Andersson L, Stevens N. Associations between early experiences with parents and well-being in old age. J Gerontol. 1993;48(3):109-116.

41. Mancini JA, Blieszner R. Social provisions in adulthood: concept and measurement in close relationships. J Gerontol. 1992;47(1):14-20.

42. Bondevik M, Skogstad A. Loneliness among the oldest old, a comparison between residents living in nursing homes and residents living in the community. Int J Aging Hum Dev. 1996;43(3):181-197.

43. Saevareid HI, Thygesen E, Lindstrom TC, Nygaard HA. Association between self-reported care needs and the allocation of care in Norwegian home nursing care recipients. Int J Older People Nurs. 2012;7(1): $20-28$.

44. Kvale S, Brinkmann S. InterViews: Learning the Craft of Qualitative Research Interviewing. Thousand Oaks, CA: Sage; 2009.

45. Griffin J. The Lonely Society? London, UK: Mental Health Foundation; 2005.

46. Hauge S, Kirkevold M. Variations in older persons' descriptions of the burden of loneliness. Scand J Caring Sci. 2012;26(3):553-560.

47. Smith JM. Loneliness in older adults: an embodied experience. J Gerontol Nurs. 2012;38(8):45-53.

48. Cattan M, White M, Bond J, Learmouth A. Preventing social isolation and loneliness among older people: a systematic review of health promotion interventions. Ageing Soc. 2005;25(1):41-67.

49. Pettigrew S, Roberts M. Addressing loneliness in later life. Aging Ment Health. 2008;12(3):302-309.

50. Kirkevold M, Moyle W, Wilkinson C, Meyer J, Hauge S. Facing the challenge of adapting to a life "alone" in old age: the influence of losses. J Adv Nurs. 2013;69(2):394-403.

CAS, Scopus and the Elsevier Bibliographic databases. The manuscript management system is completely online and includes a very quick and fair peer-review system, which is all easy to use. Visit http://www.dovepress. com/testimonials.php to read real quotes from published authors. 